\title{
Improving haemophilia diagnosis in developing countries: the Malian experience
}

YL Diallo, A Poudiougo, BSI Drame, AS Traore, Y Cissoko, M Doumbere, H Kone, Z Sountoura, AA Diakite, AT Sidibe, JF Schved

Introduction: Around $90 \%$ of all undiagnosed people with haemophilia (PWH) live in developing countries. In Mali, in sub-Saharan Africa, nearly $90 \%$ of potential PWH are not identified. We initiated a two-year study involving an integrated programme

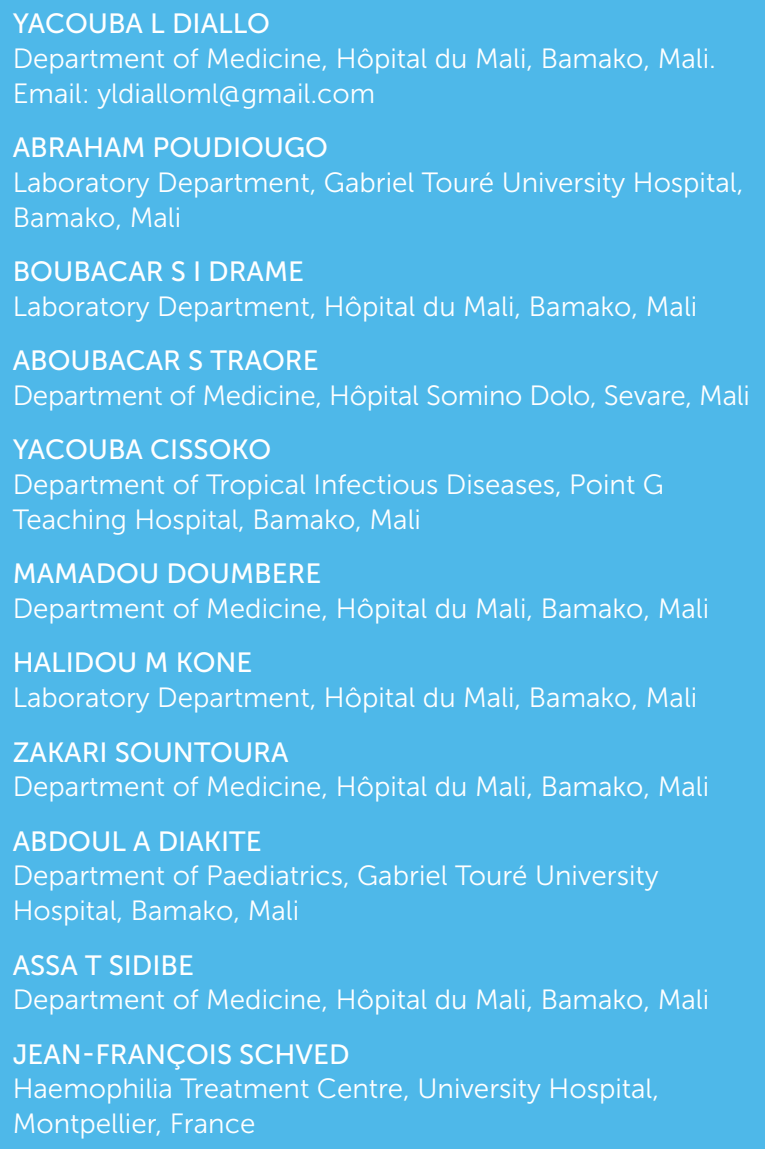

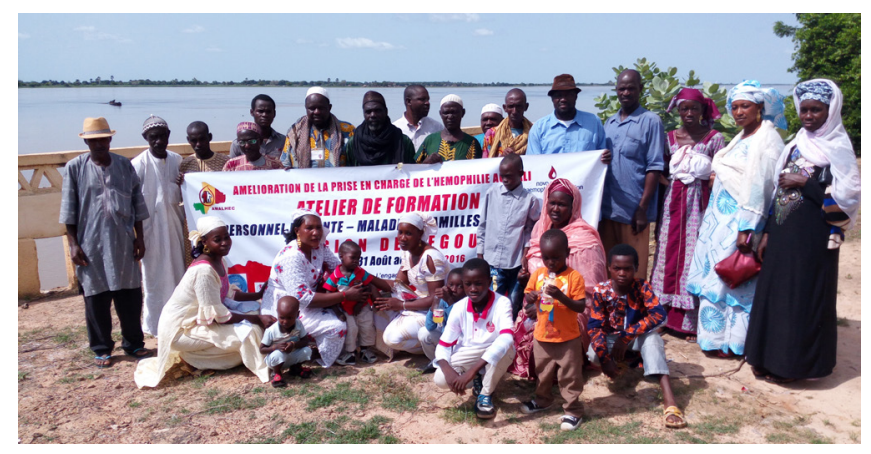

Haemophilia patients and their families after a training session in Segou, Mali.

A programme of training sessions targeting all relevant stakeholders - including health care professionals, traditional healers, families and media workers - has helped to improve the diagnosis of bleeding disorders in Mali, and provides a model that may be beneficial in other developing countries.

of training and awareness-raising with the aim of improving diagnosis and access to care for $\mathrm{PWH}$, based on partnership with those who regularly interact with them. Methodology: Our training programme focused on four regions of Mali and the district of Bamako, and included three types of health professionals from different districts and hospitals: medical doctor, nurse and laboratory technician. We also targeted traditional healers, who continue to be strongly involved in local healthcare, and provided training sessions for patients and their families on the symptoms, diagnosis, treatment and complications of haemophilia. A complementary programme of awareness-raising, including the national media, ran alongside the training sessions. Results: Overall, the programme involved 495 participants: 213 health 
care professionals, 24 patients, 79 parents of patients, 126 traditional healers, and 53 media workers. A direct result was development of collaboration between these groups in identifying haemophilia, and the transfer of four patients from a traditional healer's office to hospital for diagnosis and treatment. The number of diagnosed PWH increased from 42 in 2016 to 126 in 2017. Conclusion: The integrated haemophilia educational programme, which took into account the nature of the local environment and involved all relevant stakeholders, showed that taking a collaborative approach is a successful strategy for improving diagnosis and care for $\mathrm{PWH}$ in Mali. This approach could be relevant in other developing countries.

Keywords: Haemophilia, diagnosis, developing countries, Mali

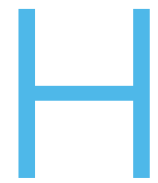

aemophilia is a rare bleeding disorder that is poorly diagnosed in developing countries. The overall prevalence at birth is estimated at 30 cases per 100000 male live births ${ }^{[1]}$.

Around the world, approximately $70 \%$ of people with haemophilia $(\mathrm{PWH})$ remain undiagnosed and therefore untreated. Among this population, nearly $90 \%$ live in developing countries, particularly in Africa ${ }^{[2]}$. Access to regular treatment with clotting factor concentrates has been shown to contribute to reduced morbidity and mortality in $\mathrm{PWH}^{[3-7]}$. However, despite the efforts of organisations such as the World Federation of Hemophilia (WFH) to improve haemophilia care globally, many African countries face difficulties in initiating haemophilia care programmes. This leads to a high rate of undiagnosed and untreated patients in these countries ${ }^{[8]}$, which in turn results in an increased rate of joint disability and poor quality of life among their haemophilia population ${ }^{[9-11]}$.

Efforts to improve haemophilia diagnosis and care in Mali, in sub-Saharan Africa, were boosted in 2012 with the establishment of a national haemophilia patients organisation, the Malian Haemophilia Society (Association Malienne de Lutte contre l'Hémophilie / AMALHEC), which is recognised as a national member organisation (NMO) of the WFH; 20 patients were registered. Following recognition of the NMO by Malian authorities, in 2014 it became part of a WFH twinning programme. Pairing with the haemophilia treatment centre in Montpellier, France, enabled development of local laboratory diagnostics and improved access to clotting factor concentrates.
Improving outreach and diagnosis of people with bleeding disorders is a strategic priority of the WFH. In the Malian context - and in other countries where bleeding disorders are under-diagnosed - we believe that involving the different groups that interact with patients can play a significant role in improving the number of patients diagnosed. This principle was behind the initiation of a project to develop a strategic, collaborative approach to improving awareness and diagnosis of haemophilia in Mali. The project involved the Malian NMO, the WFH, the Novo Nordisk Haemophilia Foundation (NNHF), and other relevant local partners.

Here, we report our experience, and share the challenges faced and lessons learned during the course of the project.

\section{METHODOLOGY}

In January 2016, we initiated an innovative two-year prospective study designed to raise awareness and improve the diagnosis of haemophilia and other bleeding disorders in Mali. The study focused on four regions of Mali (Kayes, Sikasso, Segou and Mopti) and the district of Bamako, the capital city. Here, we report the main overall results and detailed results from the Sikasso group.

With the help of the Malian NMO, we sought to promote an integrated approach to building capacity in the diagnosis of haemophilia based on training and awareness-raising, taking into account strategies previously reported in the literature - for example, in a single treatment centre in Senegal and building a national haemophilia treatment network in Brazil - and the standards proposed for economically developing countries ${ }^{[12-15]}$. It was also important to consider the local environment and healthcare landscape, and to include all relevant stakeholders.

Those targeted included medical doctors, nurses and laboratory technicians; traditional healers, who continue to play a significant role in healthcare in Mali; opinion leaders and the media; and haemophilia patients and their families. The healthcare department of the Malian armed forces (Services de Santé des Armées) was also included, as it is involved in the treatment and provision of care for both civilian and military patients.

The training sessions were delivered by health care professionals using both oral and video content, and included information about haemophilia symptoms, diagnosis, treatment and complications. The sessions were multidisciplinary. Theoretical training was followed up with practical sessions in the trainees' 


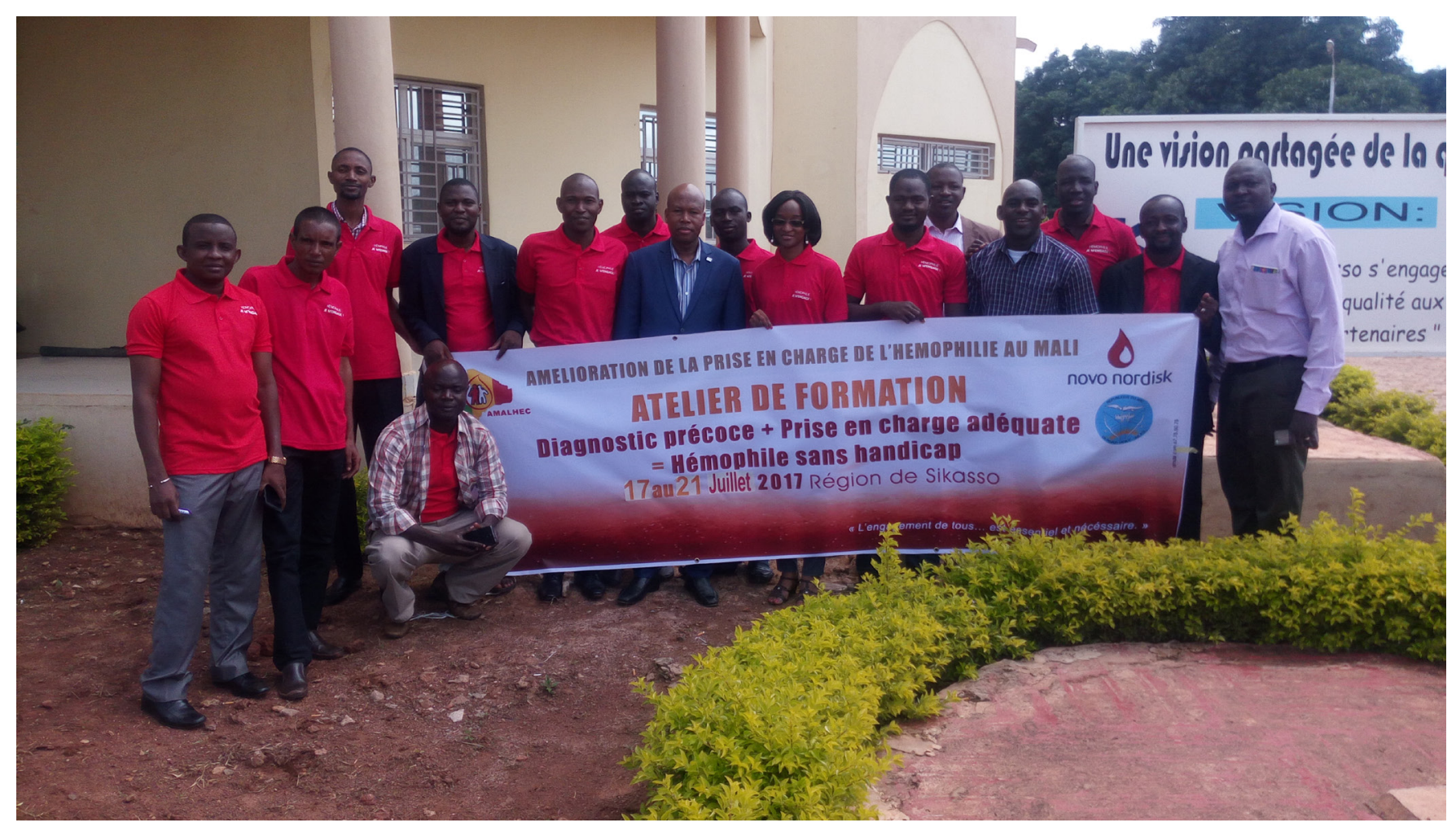

Physicians after a training session in Sikasso, Mali

hospital laboratory. Learning was enriched by patient testimonials provided by the Malian Haemophilia Society. Before and after each session, the effectiveness of training was determined by formal assessment (10 questions about haemophilia and its management). The sessions were complemented by awareness-raising activities, including public or professional meetings, television and radio broadcasts, and meetings with health authorities, students and media organisations.

Through the training sessions, participants developed a local strategy for identifying people with haemophilia and including them in the national bleeding disorder registry. A suspected case was defined as a patient with a familial or personal bleeding history. Individuals in whom haemophilia was suspected were referred to the district hospital for measurement of prothrombin time (PT) and activated partial thrombin time (aPTT). Alternatively, patients could be identified when routine blood testing revealed coagulation abnormalities - for example, during preparation for surgery. Patients with evidence of abnormal coagulation were then referred to the haemophilia treatment centre to confirm the diagnosis, obtain treatment and join the register of bleeding disorders. With the involvement of the Malian Department for Traditional Medicine (within the National Institute for Research on Public Health, part of the Ministry of Health), we organised special training sessions for traditional healers in each region. They were informed of the study and invited to refer their patients for hospital investigation if signs and symptoms led them to suspect a bleeding disorder.

\section{Involving partners}

The training sessions were supported by the Novo Nordisk Haemophilia Foundation (NNHF), the haemophilia treatment centre in Montpellier, France, and the Department of Medicine at the Hôpital du Mali in Bamako. All training courses were facilitated by Malian Health Directorate and the Malian Haemophilia Society.

Anti-haemophiliac clotting factor concentrates were generously provided by the WFH through a humanitarian aid programme.

\section{Analysis}

The primary endpoints were the number of laboratory blood tests performed and the number of newly diagnosed patients during the period January 2016 - December 2017. The data collected were analysed using SPSS 14 statistics software.

\section{RESULTS}

Training activities

Overall, the programme included 495 participants: 213 health care professionals, 24 patients, 79 parents of patients, 126 traditional healers and 53 media workers (see Figure 1). 
Figure 1. Participant distribution by occupation

1a. Total study population

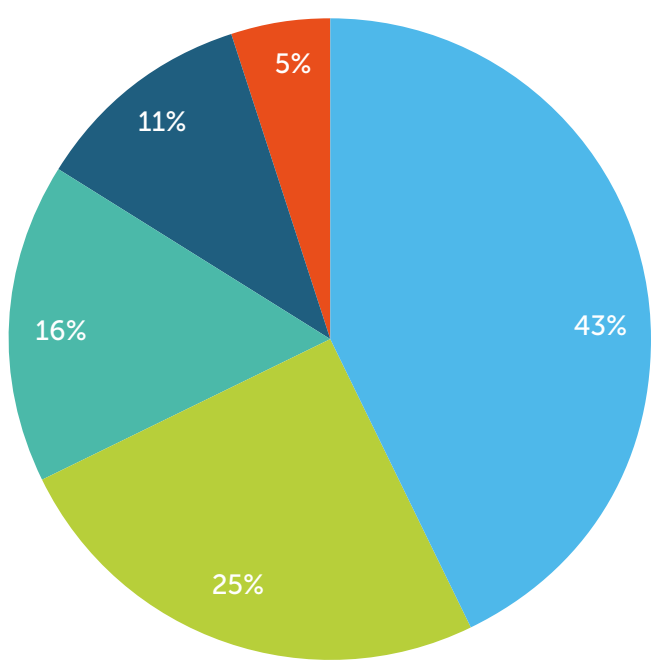

Health professionals
Family members

Patients

Between January 2016 and December 2017, the programme organised 15 training sessions for health care professionals, five sessions for traditional practitioners, seven sessions for patients and their families, and one session for media workers. Before and after assessments of knowledge in health professionals demonstrated an increase in awareness and understanding of haemophilia. For example, in 1b. Health professionals

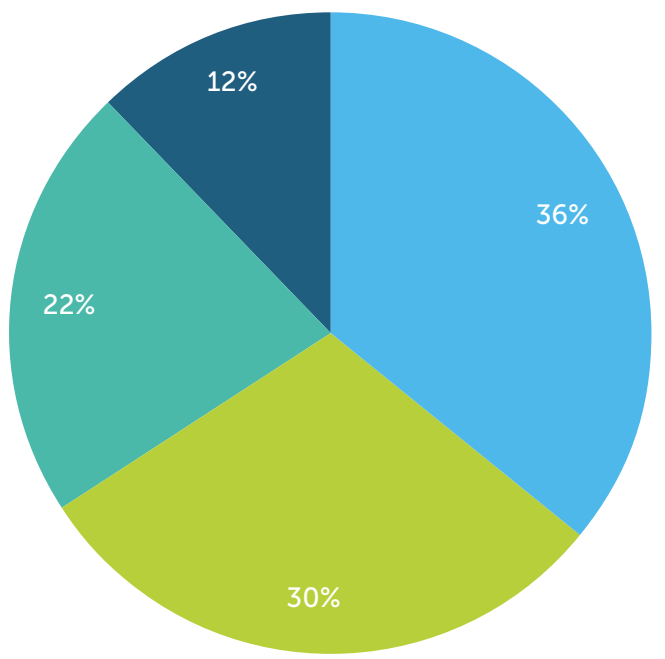

Nurses

Lab technicians
Generalist physicians

Specialist physicians

the session conducted in Kayes, the mean score in the formal assessment was $56.8 \%$ before the session and $76.8 \%$ afterwards. For the session in Sikasso, the mean scores before and after training were $56.9 \%$ and $84.6 \%$ respectively for nurses, $51.5 \%$ and $86 \%$ for lab technicians, and $58.5 \%$ and $86.7 \%$ for physicians. The scores for health professionals show a relative improvement of around $50-75 \%$ (Figure 2).

Figure 2. Assessment scores before and after training in nurses (N), laboratory technicians (LT) and physicians (P) in Sikasso (TM = overall mean)

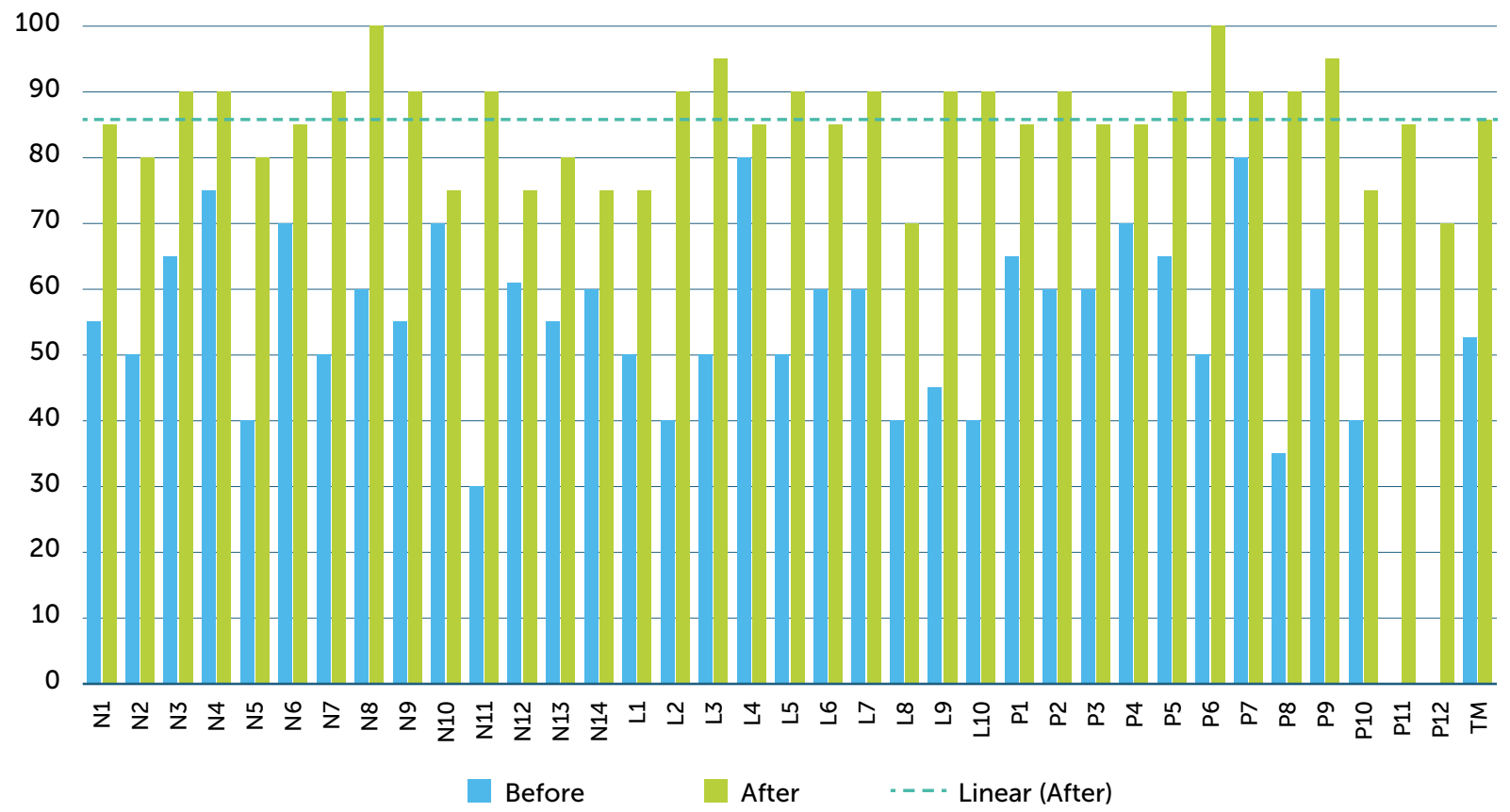


Table 1. Outcome of referrals

\begin{tabular}{|c|c|c|}
\hline \multicolumn{2}{|c|}{$\begin{array}{l}\text { ALL PATIENTS REGISTERED WITH } \\
\text { BLEEDING DISORDERS BY END OF } \\
\text { STUDY }\end{array}$} & $N=126$ \\
\hline \multicolumn{2}{|l|}{ Haemophilia A } & 102 \\
\hline \multicolumn{2}{|l|}{ Haemophilia B } & 8 \\
\hline \multicolumn{2}{|c|}{ Von Willebrand disease } & 12 \\
\hline \multicolumn{2}{|l|}{ Afibrinogenemia } & 1 \\
\hline \multicolumn{2}{|c|}{ Factor VII deficiency } & 1 \\
\hline \multicolumn{2}{|c|}{ Factor XIII deficiency } & 1 \\
\hline \multicolumn{2}{|l|}{ Thrombocytopenia } & 1 \\
\hline \multicolumn{2}{|c|}{$\begin{array}{l}\text { Total referred with suspected } \\
\text { bleeding disorder during the study }\end{array}$} & 121 \\
\hline \multicolumn{2}{|c|}{$\begin{array}{l}\text { Number of patients for whom lab } \\
\text { tests were carried out }\end{array}$} & 120 \\
\hline \multicolumn{2}{|c|}{$\begin{array}{l}\text { Number of tests not confirming a } \\
\text { bleeding disorder }\end{array}$} & 29 \\
\hline \multicolumn{2}{|c|}{ Number of patients not tested } & 7 \\
\hline \multicolumn{2}{|c|}{$\begin{array}{l}\text { Number of people newly diagnosed } \\
\text { with haemophilia }\end{array}$} & 84 \\
\hline \multicolumn{3}{|l|}{$\begin{array}{l}\text { OF ALL } \\
\text { REGISTERED } \\
\text { PATIENTS WITH } \\
\text { HAEMOPHILIA } \\
(\mathrm{N}=110)\end{array}$} \\
\hline Severe & 83 & 1 \\
\hline Moderate & 9 & 5 \\
\hline Mild & 10 & 2 \\
\hline
\end{tabular}

\section{Impact on clinical activities}

The outcome of the referrals is summarised in Table 1.

Of the 121 patients referred, one did not undergo laboratory testing due to lack of facilities. Eighty-four patients were newly diagnosed with haemophilia. Twenty-nine tests did not confirm a bleeding disorder, and tests could not be carried out in seven patients due to limited laboratory facilities. Traditional practitioners identified seven patients from four families with a suspected bleeding disorder. A diagnosis of severe haemophilia was established in three; tests were unavailable for three and the seventh was lost to follow up.

The number of patients registered with the Malian Haemophilia Society increased following the programme. There were 20 registered patients in 2012, 42 at the beginning of the study period in 2016 (26 with haemophilia) and 126 in December 2017. (Some registered patients were referred for tests during the study and are included in Table 1.) This increase was associated with a marked increase in demand for clotting factor concentrates supplied as part of the WFH humanitarian aid programme (Figure 3). This has enabled the provision of low-dose prophylaxis to all patients under five years old, with the potential to improve their quality of life and reduce the risk of joint bleeds and long-term complications.

Figure 3. Clotting factor concentrate donated by the World Federation for Hemophilia (international units)

$1,600,000$

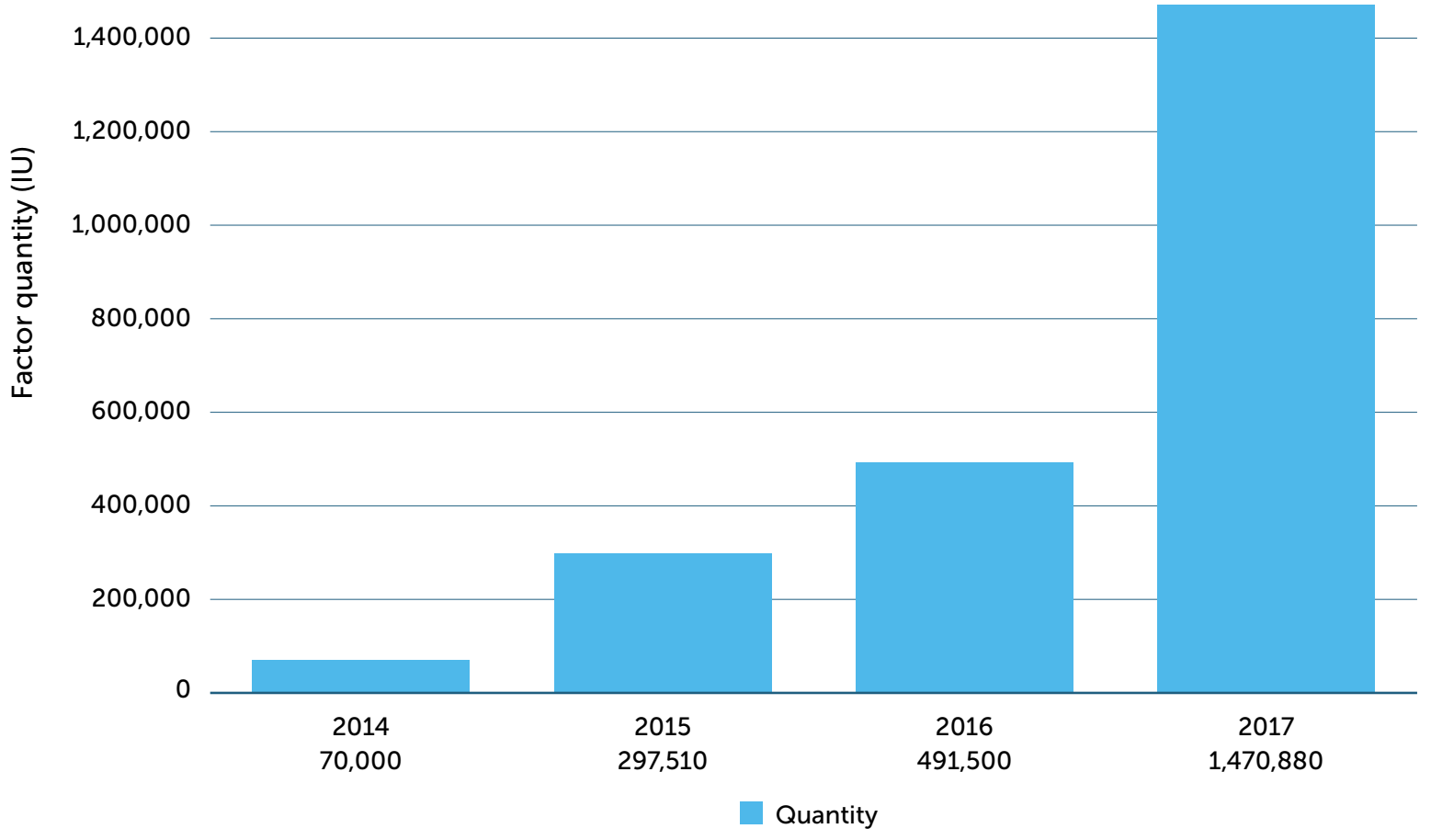


Impact on the haemophilia social environment An important direct impact of the programme was the development of collaboration between patients and their families and traditional healers. Involving traditional healers in the detection of new patients is an original approach and an important step in engaging the community to increase awareness.

Progress has also been made in raising awareness of haemophilia among the Malian population more widely. Awareness-raising activities were further strengthened through a WFH twinning programme between the Algerian Haemophilia Association (Association Nationale des Hémophiles Algériens) and the Malian Haemophilia Society in 2017. This resulted in greater media coverage: radio and television stations are now much more interested in awarenessraising activities about haemophilia and other bleeding disorders.

\section{DISCUSSION}

The underdiagnosis of haemophilia and other bleeding disorders in developing countries has prompted the WFH to focus its strategy on improving haemophilia care in these areas, through reducing the number of undiagnosed patients, increasing access to treatment, reducing joint disabilities, and generally improving quality of life for $\mathrm{PWH}^{[2]}$. To work on the ground, it is important that any strategy takes into account the realities of the population and their environment. Our approach in Mali was to provide an integrated programme to improve awareness and diagnosis of haemophilia, involving all relevant stakeholders, thereby improving access to care through an innovative strategy based on three pillars:

- The identification of social aspects particular to the local population, such as faith, culture and economic capacity

- The evaluation of methods, strategies and results reported in the literature about programmes in other countries to ascertain how applicable they are locally, and to avoid any potential conflict of interest

- Maintaining relationships with all parties involved to ensure the best outcomes for actions or activities initiated by the programme, based on the best combination of existing and new approaches.

Ideally, this approach is a collaborative model that involves the WFH, laboratories, patients and their families, the government, healthcare providers, and other relevant local stakeholders.
In many African countries, the population continues to approach traditional healers for solutions to problems with their health ${ }^{[16]}$. Around $80 \%$ of the Malian population believe in traditional medicine and use it as the first point of access for the treatment of health issues ${ }^{[16]}$. In Africa, bleeding diseases are frequently associated with traditional belief and myth, such as offending traditional spiritual laws and witchcraft. Additionally, traditional opinion leaders, including religious and local leaders, play a crucial rule in African society, and their influence can have a positive or negative impact on the popular acceptance of any new idea or project ${ }^{[17,18]}$. To ensure the successful implementation of a programme that aims to improve haemophilia care in this environment, it therefore is important to take these elements into consideration.

Good collaboration between traditional healers, patient families, opinion leaders and health care professionals during the study led to in an increase in newly diagnosed patients. Improving the knowledge of traditional healers resulted in their involvement in transferring patients from their own offices to treatment centres. Participants in the training sessions had the opportunity to ask questions and did so regularly, which we believe is also an indicator of their success.

The synergy between the WFH and NNHF made it possible to provide training, diagnosis and care for a variety of stakeholders. The training sessions and awareness-raising activities were supported by the NNHF, while diagnostic facilities, drugs for synovitis and clotting factors were covered by the WFH twinning and humanitarian aid programmes. In developing countries with limited resources, such as those found across sub-Saharan Africa, this kind of collaboration has huge benefits for capacity building and improvement in haemophilia care.

Haemophilia is a rare disease which receives little attention in comparison to the tropical infectious diseases prevalent on the African continent. Involving local opinion leaders could be the best way to improve this situation in Africa, as the population is generally more willing to listen to them. Their endorsement could be key to the success of raising awareness of haemophilia and other bleeding disorders.

Implementing haemophilia care in an environment where there is little or no access to treatment is a step-by-step process that requires consideration of local culture, faith and other social aspects if it is to be successful. WFH guidance stresses the importance of patient organisations in developing haemophilia care. 
This requires a great degree of motivation and, in the context of sub-Saharan Africa, may also carry a risk of stigmatising patients. It is perhaps more practical for health care professionals to take the first steps towards developing and improving the care environment. Following this lead, special research and training programmes, participation in patient meetings, and the advocacy of health care professionals would then enable new patient organisations to grow in such a way that they are sustainable.

\section{CONCLUSION}

Capacity building and improving care for haemophilia and other rare bleeding disorders in developing countries can be achieved if the local environment and all relevant stakeholders are taken into account. In the case of Mali, this involved the inclusion of patients and their families, health care providers and traditional healers in a training programme, and an awarenessraising campaign linked with the national media. This has proven to be a successful strategy, resulting in an increase in the number of patients diagnosed with haemophilia and linked to care. As such, it may serve as a beneficial model to follow in other developing countries where haemophilia and other bleeding disorders are under-diagnosed.

\section{ACKNOWLEDGEMENTS}

The authors have advised no interests that might be perceived as posing a conflict or bias. The training programmes in the study were supported by the Novo Nordisk Haemophilia Foundation. Writing assistance was provided by Steve Chaplin, Haemnet.

This paper reports on the results of an education and awareness programme designed to raised diagnostic rates. No patient identifiable data are included. The programme was the subject of a poster presentation at the World Federation of Hemophilia Congress in Glasgow, Scotland, in 2018 (ref. W-MP-101(188)).

\section{ORCID}

Yacouba L Diallo (iD https://orcid.org/0000-0003-0812-5652 Abraham Poudiougo (iD) https://orcid.org/0000-0002-4930-7068 Boubacar SI Drame (iD https://orcid.org/0000-0003-0107-8910 Aboubacar S Traore (iD https://orcid.org/0000-0002-2372-2618 Yacouba Cissoko (iD https://orcid.org/0000-0002-4819-3118 Mamadou Doumbere (iD) https://orcid.org/0000-0002-9762-7832 Halidou M Kone (iD) https://orcid.org/0000-0003-3980-624 Zakari Sountoura (iD https://orcid.org/0000-0001-8461-7216 Abdoul A Diakite (iD https://orcid.org/0000-0002-9014-1880 Assa T Sidibe (iD https://orcid.org/0000-0003-3051-8954 Jean-François Schved (iD) https://orcid.org/0000-0003-0332-3254

\section{REFERENCES}

1. Iorio A, Stonebraker JS, Chambost H, et al.; Data and Demographics Committee of the World Federation of Hemophilia. Establishing the prevalence and prevalence at birth of hemophilia in males: a meta-analytic approach using national registries. Ann Intern Med 2019 Sep 10. doi: 10.7326/ M19-1208.

2. O'Mahony B, Black C. Expanding haemophilia care in developing countries. Semin Thromb Hemost 2005; 31(5): 561-8.

3. Manco-Johnson MJ, Abshire TC, Shapiro AD, et al. Prophylaxis versus episodic treatment to prevent joint disease in boys with severe haemophilia. N Engl J Med 2007; 357: 535-44. doi: 10.1056/NEJMoa067659.

4. Ferreira AA, Bustamante-Teixiera MT, Gonçalves Leite IC, et al. Clinical and functional evaluation of the joint status of haemophiliac adults at a Brazilian blood center. Rev Bras Hematol Hemoter 2013; 35(1): 23-8. doi: 10.5581/15168484.20130010.

5. van den Berg HM, Fischer K, Mauser-Bunschoten EP, et al. Long-term outcome of individualized prophylactic treatment of children with severe haemophilia. Br J Haematol 2001; 112(3): 561-5. doi: 10.1046/j.1365-2141.2001.02580.x.

6. Gouider E, Jouini L, Achour M, et al. Low dose prophylaxis in Tunisian children with haemophilia. Haemophilia 2017; 23(1): 77-81. doi: 10.1111/hae.13048.

7. Giangrande PL, Black C. World Federation of Haemophilia programs in developing countries. Semin Thromb Hemost 2005; 31(5): 555-60. doi: 10.1055/s-2005-922227.

8. World Federation of Haemophilia. Report on the Annual Global Survey 2016. Available from https://www1.wfh.org/ publications/files/pdf-1690.pdf (accessed 14 April 2020).

9. Beyan C, Kaptan K, Ifran A. Hemophilic arthropathy in nonsevere haemophiliacs. Rheumatol Int 2007; 27(5): 501-2. doi: 10.1007/s00296-006-0246-9.

10. Gurcay E, Eksioglu E, Ezer U, Tuncay R, Cakci A. Functional disability in children with hemophilic arthropathy. Rheumatol Int 2006; 26(11): 1031-5. doi: 10.1007/s00296-006-0115-6.

11. Monahan PE, Doria AS, Ljung R, Jiménez-Yuste V. Optimizing joint function: new knowledge and novel tools and treatments. Haemophilia 2012; 18 Suppl 5: 17-26. doi: 10.1111/j.1365-2516.2012.02888.x.

12. Diop S, Seck M, Sy-Bah D, et al. Implementing haemophilia care in Senegal, West Africa. Haemophilia (2014), 20, 73-77. doi: $10.1111 /$ hae.12249.

13. Antunes SV. Haemophilia in the developing world: the Brazilian experience. Haemophilia (2002), 8, 199-204. doi: 10.1046/j.1365-2516.2002.00638.x.

14. Isarangkura P. Haemophilia care in the developing world: benchmarking for excellence. Haemophilia (2002), 8, 205210. doi: 10.1046/j.1365-2516.2002.00600.x.

15. Donnelly J. Patient Outreach Guide for Hemophilia and Other Bleeding Disorders. World Federation of Hemophilia. World Federation of Hemophilia, 2008. Available from http://www1. wfh.org/publications/files/pdf-1401.pdf (accessed 14 April 2020).

16. Sanogo R. Medicinal plants traditionally used in Mali for dysmenorrhea. Afr J Tradit Complement Altern Med 2011; 8(5 Suppl): 90-6. doi: 10.4314/ajtcam.v8i5S.4. 
17. Gabriel Weimann DHT, van Vuuren D, Jouber JPR. Looking for opinion leaders: traditional vs. modern measures in traditional societies. International Journal of Public Opinion Research 2007; 19(2): 173-90. doi: 10.1093/ijpor/edm005.

18. Kolawole A. Analysis of the influence of opinion leaders on voting decision of rural voters: an evidence from Ayetoro, Ogun-State of Nigeria. IOSR Journal of Humanities and Social Science 2016; 21(1): 46-53. doi: 10.9790/0837-21134653.
HOW TO CITE THIS ARTICLE:

Diallo YL, Poudiougo A, Drame BSI, Traore AS, Cissoko Y, Doumbere M, Kone H, Sountoura Z, Diakite AA, Sidibe AT, Schved JF. Improving haemophilia diagnosis in developing countries: the Malian experience. J Haem Pract 2020; 7(1) 45-52. https://doi.org/10.17225/jhp00135.

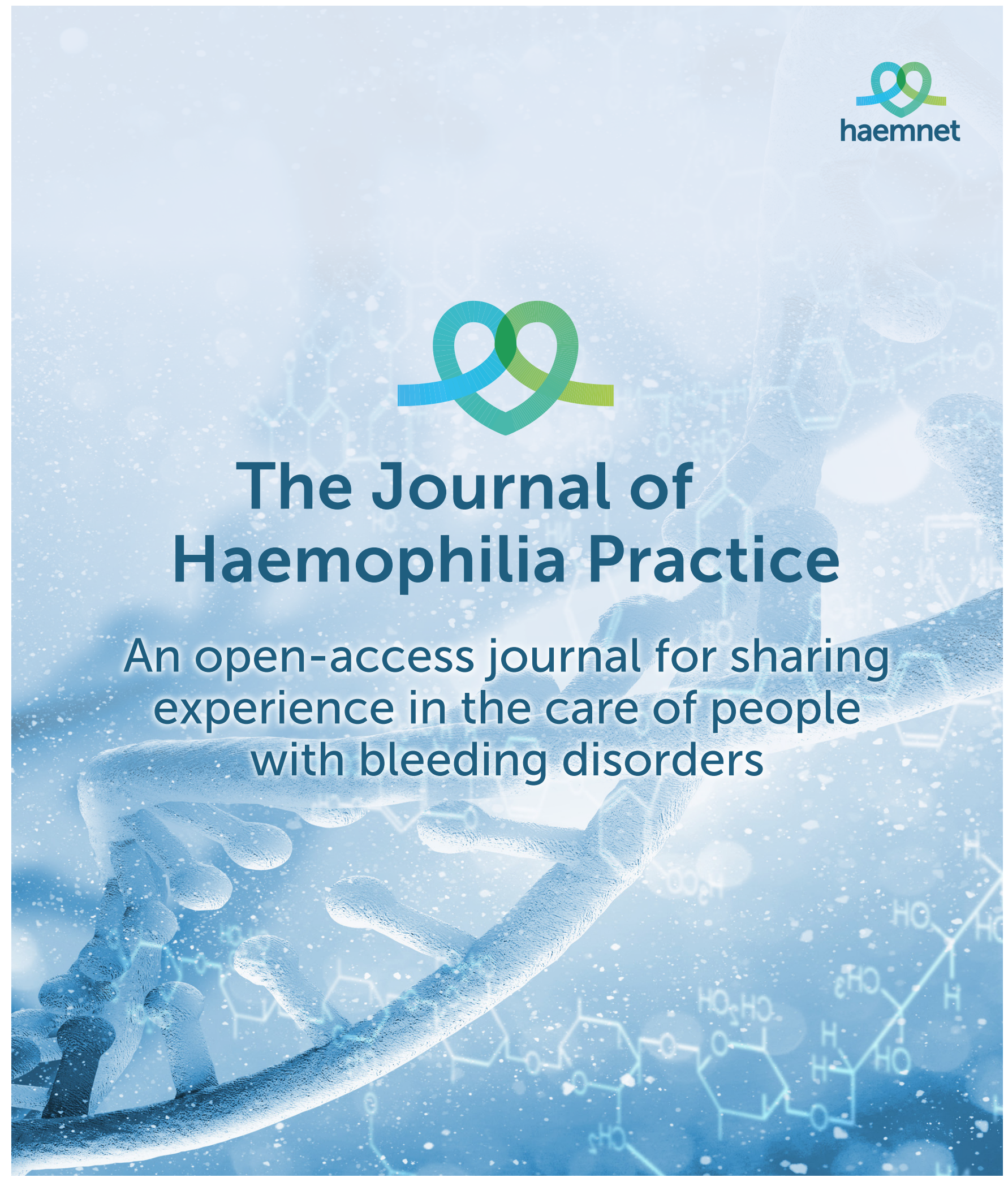

